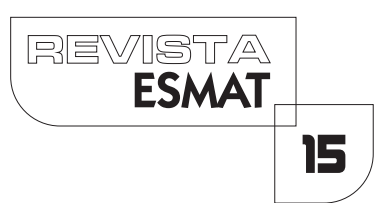

\title{
DIREITOS SOCIAIS E PATERNALISMO NO CONTEXTO DO ESTADO SOCIAL
}

\author{
SOCIAL RIGHTS AND PATERNALISM IN THE CONTEXT OF THE SOCIAL STATE
}

Marcos Augusto Maliska

Marcos Augusto Maliska é doutor em Direito Constitucional (UFPR/LMU-Munique/2003) com estudos de Pós-Doutorado no Instituto Max Planck de Heidelberg, Alemanha (20 l 0-20 I 2). Professor do Programa de Mestrado em Direitos Fundamentais e Democracia do Centro Universitário em Curitiba (UniBrasil).Procurador Federal. E-mail:marcosmaliska@yahoo.com.br

Fabrício Carvalho

Fabrício Carvalho é mestre em Direitos Fundamentais e Democracia, pelo Centro Universitário Autônomo do Brasil (UniBrasil); pós-graduado em Direito Constitucional, pela ABDConst; e graduado em Direito, pelo UniBrasil. Trabalha na Polícia Militar do Paraná. E-mail: fabriciocarvalho.fc@hotmail.com

\section{RESUMO}

O presente trabalho trata das relações entre paternalismo e direitos sociais. $\bigcirc$ princípio social, adotado pelo Estado sobretudo após a Segunda Guerra Mundial, ampliou significativamente o campo de atuação estatal, abrindo um maior caminho para as críticas antipaternalistas. A principal crítica ao paternalismo diz respeito à restrição que ele impõe à autonomia da pessoa - autonomia como capacidade de escolha. Por seu turno, o Estado Social assumiu como tarefas, entre outras, a garantia dos direitos sociais e a uniformização das condições de vida social, que implicam maior intervenção estatal. Assim, o presente artigo procurou afirmar a necessidade de se adequar a crítica antipaternalista às tarefas do Estado Social, bem como demonstrar que, embora nem toda ação paternalista seja justificável, algumas ações paternalistas podem se justificar pelo consentimento - expresso ou hipotético - da pessoa à qual se dispensa um tratamento paternalista. Conclui-se, ao final, que o Estado Social tem a difícil tarefa de intervir na sociedade para promover os direitos sociais - e os direitos fundamentais como um todo -, ao mesmo tempo em que precisa respeitar, na maior medida possível, o direito à autonomia dos indivíduos.

PALAVRAS-CHAVE: Direitos Sociais; Autonomia; Paternalismo; Estado Social. 


\begin{abstract}
This paper deals with the relationship between paternalism and social rights. The social principle, adopted by the State especially after World War II, significantly expanded the state's field of action, opening a greater path to anti-paternalist critique. The main criticism of paternalism concerns the restriction it imposes on the autonomy of the person - autonomy as the capacity for choice. For its part, the Social State has assumed, among other tasks, the guarantee of social rights and the standardization of social conditions, which imply an increase in the level of State intervention. Thus, the present article sought to affirm the need to adapt anti-paternalist critique to the tasks of the Social State, and to demonstrate that, although not all paternalistic actions are justifiable, some paternalistic actions may be justified by the consent - expressed or hypothetical - of the person to whom paternalistic treatment is given. At the end, it is concluded that the Social State has the hard task of intervening in society to promote social rights while at the same time must respect, as much as possible, the right to autonomy of individuals.
\end{abstract}

KEYWORDS: Social Rights; Autonomy; Paternalism; Social State.

\title{
I INTRODUÇÃO
}

As Constituições mexicana (1917) e de Weimar (1919) afirmaram o Estado Social como uma tentativa de superação do modelo liberal de Estado. Diferentemente do que ocorria no Estado Liberal, no qual as intervenções praticamente se limitavam a promover medidas de polícia em determinados setores da sociedade, o Estado Social passa a realizar uma gama de tarefas, de modo que sua atuação alcança diversas áreas da vida do cidadão.

Essa maior intervenção estatal, por sua vez, abriu, na mesma medida, mais espaço para a crítica antipaternalista. $\bigcirc$ antipaternalismo, ideologia dominante nos países desenvolvidos, rechaça aquelas intervenções que de algum modo restrinjam a autonomia dos indivíduos. Assim, pode-se afirmar que se estabeleceu uma espécie de tensão entre a crítica antipaternalista e as atividades interventivas do Estado Social. Isso porque quanto maior o grau de intervenção do Estado na sociedade, maior é a possibilidade de se adotarem medidas paternalistas, ou seja, medidas que interferem em maior ou menor medida - na autonomia dos destinatários das ações paternalistas.

Todavia, a crítica antipaternalista quando direcionada a ações estatais promovidas no interior de países em desenvolvimento parece sofrer uma espécie de "descontextualização" - haja vista que é retirada do contexto social, econômico e político em que foi desenvolvida, passando a ser aplicada num ambiente diverso, no qual a autonomia dos indivíduos, muitas vezes, é limitada pela escassez de recursos e pelo 
déficit de realização de direitos básicos, como alimentação, saúde, educação e trabalho.

Portanto, tratando-se de países em desenvolvimento, a ação estatal é de fundamental importância para a realização dos direitos sociais e para a garantia de uma liberdade real. Nesse sentido, os direitos sociais parecem se caracterizar como verdadeiros pressupostos para o exercício dos direitos de liberdade, haja vista que não se pode imaginar que possa gozar de liberdade ou autonomia uma pessoa que não tem seu direito à alimentação, à saúde etc., garantido.

Nos países do sul, como se sabe, a garantia dos direitos fundamentais e o nível de desenvolvimento da democracia se encontram significativamente mais baixos que nos países do norte. Dessa forma, a não intervenção estatal em países de economia periférica pode significar a perpetuação de uma situação de violação de direitos fundamentais e de fragilidade democrática.

Nesse aspecto, e considerando que parece não ser possível garantir os direitos fundamentais num ambiente hostil à democracia, a análise do paternalismo parece exigir que se considere, ainda, a estreita relação entre direitos fundamentais, democracia e Estado Social.

O primeiro tópico deste trabalho procurou demonstrar justamente essa relação de dependência recíproca entre direitos fundamentais e democracia, buscando aclarar ainda que de forma significativamente breve - a função que o Estado vem desempenhando historicamente no desenvolvimento dessas categorias. Para isso, buscou-se apoio tanto histórico quanto doutrinário.

No segundo tópico, tratou-se do nascimento e das características dos direitos fundamentais sociais, bem como da relação destes com o modelo de Estado Social. Nesse ponto, procurou-se reafirmar a noção - já constatada historicamente - de que os direitos de liberdade, de tradição liberal, a despeito de sua indiscutível importância, não foram - e continuam não sendo - instrumentos suficientes para promover uma vida digna para a maior parte das pessoas.

No último tópico, procurou-se delimitar a noção de paternalismo, trazendo conceitos de autores distintos, ao mesmo tempo em que se buscou analisar algumas das críticas antipaternalistas. Procurou-se, nesse ponto, demonstrar que algumas intervenções estatais paternalistas podem se justificar por razões de necessidade e pelo consentimento da pessoa destinatária dessa espécie de intervenção. Ainda, buscou-se demonstrar que determinadas intervenções estatais tidas como paternalistas, como concessões do Estado, são, ao contrário, verdadeiras conquistas dos movimentos sociais que se realizaram por meio de lutas sociais ao longo do tempo.

\section{ESTADO DE DIREITO, DEMOCRACIA E DIREITOS FUNDAMENTAIS}

Nas últimas décadas do século $X X$, o Estado de Direito consolidou-se como uma das fórmulas de maior sucesso da filosofia política e da filosofia jurídica ocidentais. Após o recuo do socialismo real e a crise dos institutos representativos, a ideia de Estado de 
Direito retorna ao mundo ocidental fortemente ligada à doutrina dos direitos fundamentais. Erige-se, nesse contexto, uma teoria político-jurídica que estabelece como prioridade a tutela dos direitos do homem, aqueles direitos insculpidos em diversas constituições nacionais e convenções internacionais dos séculos $X I X$ e $X X$. Nesse cenário, posicionar-se a favor do Estado de Direito equivale a "querer que as instituições políticas e os aparelhos jurídicos tenham rigorosamente por finalidade a garantia dos direitos subjetivos". (ZOLO, 2006, p. 3-5).

A respeito da mudança na forma de se interpretar o Estado de Direito, Danilo Zolo observa o seguinte:

Contra as recorrentes interpretações formalistas do Estado de Direito, pode-se afirmar, aliás, que os seus institutos são hoje explicitamente pensados por teóricos europeu-continentais e anglo-saxões à luz de uma filosofia política "individualista"; uma filosofia que não só abandonou o organicismo social, o utilitarismo coletivista e o estatismo, mas que subordina a dimensão pública e o interesse geral ao primado absoluto dos valores e das expectativas individuais. É a realização desses valores e a satisfação dessas expectativas que os teóricos do Estado de Direito, tanto no continente europeu como no mundo anglo-saxão, assumem hoje como fonte primária de legitimação do sistema político. (ZOLO, 2006, p. 06).

José Joaquim Gomes Canotilho observa que o Estado nos dias atuais só se concebe como Estado Constitucional. Para o constitucionalista português, é fato significativo que a expressão Estado Constitucional tenha sido acolhida apenas na juspublicística mais recente. Sabe-se que o constitucionalismo procurou estruturar o Estado com determinadas qualidades - submetido ao direito, regido por leis, com separação dos poderes etc. - que fazem dele um Estado Constitucional. Assim, para que possa ser identificado como Estado Constitucional, o Estado deve ser um Estado de Direito Democrático, ou seja, deve ser, a um só tempo, Estado de direito e Estado democrático. (CANOTILHO, 2000, p. 92 e 93)

Isso significa que o Estado Constitucional moderno, para além de Estado de Direito, deve obrigatoriamente estruturar-se como Estado de direito democrático, ou seja, como uma ordem legitimada pelo povo. Assim, o poder do Estado deve organizar-se e exercer-se de modo democrático, o que faz do princípio da soberania popular um dos fundamentos do Estado Constitucional. (CANOTILHO, 2000, p. 98).

Os teóricos do Estado de Direito entendem, ainda, que para conter a tendência arbitrária do poder político, seja necessária a força do direito. $\bigcirc$ direito positivo deve estabelecer o regramento do exercício do poder, vinculando os poderes do Estado ao respeito das regras gerais e, por consequência, tornando as ações dos poderes do Estado mais transparentes e mais controláveis por parte dos cidadãos. Assim, o ordenamento jurídico no Estado moderno pretende desempenhar três funções: "a de 
instrumento da ordem e da estabilidade do grupo social, enquanto expressão normativa do poder de governo; a de mecanismo legislativo de ritualização-limitação do poder político; e aquela, estritamente correlata e complementar, de garantia dos direitos subjetivos". (ZOLO, 2006, p. 36).

Ingo Wolfgang Sarlet destaca a estreita relação existente entre direitos fundamentais e Estado Constitucional. Nas palavras do autor:

Os direitos fundamentais integram (...), ao lado da definição da forma de Estado, do sistema de governo e da organização do poder, a essência do Estado constitucional, constituindo, neste sentido, não apenas parte da Constituição formal, mas também elemento nuclear da Constituição material. Para além disso, estava definitivamente consagrada a íntima vinculação entre as ideias de Constituição, Estado de Direito e direitos fundamentais. Assim, acompanhando as palavras de Klaus Stern, podemos afirmar que o Estado constitucional determinado pelos direitos fundamentais assumiu feições de Estado ideal, cuja concretização passou a ser tarefa permanente. (SARLET, 2009, p. 58 e 59).

No entanto, a configuração do Estado Democrático de Direito não se compõe apenas da união formal dos conceitos de Estado de Direito e Estado Democrático; consiste, sobretudo, no nascimento de um conceito novo, que considera os conceitos dos elementos componentes, "mas os supera na medida em que absorve um elemento revolucionário de transformação do status quo". (SILVA, 2005, p. I 19).

A compreensão da ideia de Estado Democrático solicita a determinação dos princípios que estão contidos, ainda que implicitamente, na própria ideia de Estado Democrático. A coluna que sustenta a ideia de Estado Democrático, no entanto, é a noção de governo do povo. (DALLARI, 1998, p. 145).

Afirma-se, ainda, que o Estado Democrático é o resultado dos três grandes movimentos político-sociais dos séculos XVII e XVIII - Revolução Inglesa, Revolução Americana e Revolução Francesa -, sendo possível indicar os princípios que passaram a nortear os Estados, como imposições da democracia, por meio de uma síntese que aponta para três aspectos fundamentais: i) a supremacia da vontade popular, que levantou a questão da participação popular no governo; ii) a preservação da liberdade, traduzida pela esfera de proteção do indivíduo contra interferências arbitrárias do Estado; iii) a igualdade de direitos, traduzida pela vedação de distinção no gozo de direitos, sobretudo por razões de ordem econômica ou entre classes sociais. (DALLARI, 1998, p. | 50 e |5 I).

José Afonso da Silva, com apoio na Constituição da República, de 1988, afirma o seguinte:

A democracia que o Estado Democrático de Direito realiza há de ser um processo de convivência social em uma sociedade 
livre justa e solidária (art. $3^{\circ}$, I), em que o poder emana do povo, e deve ser exercido em proveito do povo, diretamente ou por representantes eleitos (art. $1^{\circ}$, parágrafo único); participativa, porque envolve a participação crescente do povo no processo decisório e na formação dos atos de governo; pluralista, porque respeita a pluralidade de ideias, culturas e etnias e pressupõe assim o diálogo entre opiniões e pensamentos divergentes e a possibilidade de convivência de formas de organização e interesses diferentes da sociedade". (SILVA, 2005, p. I 19).

Entretanto, a democracia materializa-se também por meio de um processo de liberação do indivíduo das formas de opressão; e tal processo não depende apenas de reconhecimento formal de determinados direitos fundamentais, mas especialmente da criação de condições econômicas que favoreçam o pleno exercício desses direitos. (SILVA, 2005, p. 120).

A democracia, vale ressaltar, é um conceito histórico. Não sendo por si um valorfim, mas um instrumento de realização de valores indispensáveis de convivência humana, que podem ser traduzidos basicamente nos direitos fundamentais, compreende-se que a historicidade destes a envolva na mesma medida, o que enriquece seu conteúdo a cada etapa do desenvolvimento social. Sob essa ótica, a democracia não é um simples conceito político abstrato e estático, mas sim "um processo de afirmação do povo e de garantia dos direitos fundamentais que o povo vai conquistando no correr da história". (SILVA, 2005, p. I 25 e I 26).

Observa-se, assim, haver uma relação de dependência recíproca entre democracia e direitos, de forma tal que não é possível referir-se àquela sem o vínculo a estes, nem garantir o desenvolvimento de um sistema de direitos fundamentais fora de um cenário democrático. (CALLEJÓN, 2013, p. 212).

\section{DIREITOS FUNDAMENTAIS SOCIAIS E ESTADO SOCIAL}

A industrialização - e os sérios problemas sociais e econômicos que dela decorreram -, as doutrinas socialistas e a constatação de que a liberdade e a igualdade meramente formais não eram capazes de produzir os efeitos esperados promoveram, no século XIX, grandes movimentos reivindicatórios e o reconhecimento paulatino de direitos, afirmando a responsabilidade ativa do Estado no tocante à justiça social. É, contudo, no século $X X$ que os direitos sociais acabaram por se consagrar em um número expressivo de Constituições, constando também em diversos pactos internacionais. (SARLET, 2009, p. 47 e 48).

Após sua introdução no constitucionalismo dos variados modelos de Estado Social, os direitos sociais, culturais e econômicos tomam uma posição de destaque no século $X X$. Paulo Bonavides observa que os direitos sociais nascem da ideologia e do pensamento antiliberal do século $X X$, ligando-se fortemente ao princípio da igualdade, 
"do qual não se podem separar, pois fazê-lo equivaleria a desmembrá-los da razão de ser que os ampara e estimula". (BONAVIDES, 2008, p. 564).

Assim como os direitos civis e políticos, os direitos sociais "foram inicialmente objeto de uma formulação especulativa em esferas filosóficas e políticas de acentuado cunho ideológico". Depois de afirmados nas declarações solenes das Constituições marxistas e no constitucionalismo da social-democracia, sobretudo a de Weimar, os direitos de segunda geração "dominaram por inteiro as Constituições do segundo pós-guerra". (BONAVIDES, 2008, p. 564).

Importa destacar que os direitos sociais, assim como os de primeira geração, dirigem-se à pessoa individual, assim, não se confundem com os direitos coletivos e/ou difusos da terceira dimensão. (SARLET, 2009, p. 48).

Ingo Wolfgang Sarlet afirma que os direitos sociais

[...] podem ser considerados uma densificação do princípio da justiça social, além de corresponderem a reivindicações das classes menos favorecidas, de modo especial da classe operária, a título de compensação, em virtude da extrema desigualdade que caracterizava (e, de certa forma, ainda caracteriza) as relações com a classe empregadora, notadamente detentora de um maior ou menor grau de poder econômico. (SARLET, 2009, p. 48).

Dessa forma, os direitos sociais surgem como instrumentos redutores de desigualdades, segundo a máxima de que se deve tratar igualmente os iguais e desigualmente os desiguais, na medida da sua desigualdade. (MENDES; BRANCO; GONET, 201 I, p. 7I0).

Importa observar, ainda, que os direitos sociais - tanto quanto os direitos civis e políticos - encontram-se fortemente ligados à noção de cidadania. Adela Cortina observa que o conceito de cidadania que se tornou padrão foi o de "cidadania social", tal como concebido por Thomas H. Marshall. A partir desse padrão, será chamado cidadão aquele que, no interior de uma comunidade política, goze não apenas de direitos civis e políticos, mas também de direitos sociais, como o direito ao trabalho, à educação, à saúde, à moradia etc. (CORTINA, 2005, p. 5I)

Dessarte, a defesa dos direitos sociais - assim como dos direitos civis e políticos caracteriza-se como pressuposto ético do Estado Social de Direito, e, desse modo, "a exigência que apresenta é uma exigência ética de justiça, que deve ser atendida por qualquer Estado que queira se pretender legítimo". (CORTINA, 2005, p. 59).

Ainda sobre o compromisso ético do Estado Social, Luis Manuel Fonseca Pires escreve:

Estado de Direito precisava prosseguir na liberdade, ser liberal, necessitava promover e respeitar a igualdade como seu consectário natural, mas a justiça social, percebeu-se, depende de sobrepor-se em perdão e solidariedade, ou em uma palavra, 
em fraternidade.

Este é o compromisso ético-jurídico do Estado de Direito Social e Democrático que se encontra asseverado na Declaração Universal dos Direitos Humanos, proclamada em 1948, e desde logo em seu primeiro artigo: "Todas as pessoas nascem livre e iguais em dignidade e direitos. São dotadas de razão e consciência e devem agir em relação umas às outras com espírito de fraternidade". (PIRES, 2012, p. 96).

Dessa forma, enquanto o Estado Liberal de Direito assegurava a garantia das liberdades individuais, o Estado Social de Direito, por sua vez, não apenas acolhe os valores jurídico-políticos construídos pelo liberalismo burguês, mas também abraça novo conteúdo axiológico, nascendo assim os direitos às prestações do Estado. (STRECK; MORAIS, 2003, p. 91).

No entanto, mesmo no Estado Social de Direito a questão da igualdade não é resolvida, embora sobrepuje a sua dimensão meramente formal, proclamada no Estado Liberal de Direito. Por esse motivo, entre outros, desenvolve-se um novo modelo, na tentativa de conjugar o ideal democrático ao Estado de Direito; um modelo próprio que conjugue "as conquistas democráticas, as garantias jurídico-legais e a preocupação social", constituindo um novo conjunto no qual a preocupação fundamental é a transformação do status quo. (STRECK; MORAIS, 2003, p. 92).

○ conceito de Estado Social (e Democrático) de Direito, portanto, carrega as noções de certo grau de intervenção do Estado na atividade econômica, objetivando garantir aos particulares um mínimo de igualdade material e liberdade real na vida em sociedade, bem como promover medidas que assegurem a existência de condições materiais mínimas para uma existência digna. Esse modelo de Estado realiza-se mediante os procedimentos, a forma e os limites próprios do Estado de Direito; de outro modo, trata-se de um Estado de Direito que objetiva a realização da justiça social. (SARLET, 200 I , pp. 3 e 4).

A justiça social, por seu turno, só pode ser estabelecida num contexto de respeito e promoção dos direitos fundamentais, entre os quais se encontram os direitos sociais.

Tratando dos direitos fundamentais sob a perspectiva internacional, Flávia Piovesan afirma que a Constituição, de 1988, abraçou a ideia da universalidade dos direitos humanos, haja vista consagrar o valor da dignidade da humana como princípio fundamental do modelo de constitucionalismo iniciado em 1988. (PIOVESAN, 20 I4, p. 410).

A mesma autora observa que

O texto constitucional ainda realça que os direitos humanos são tema de legítimo interesse da comunidade internacional, ao imediatamente prever, dentre os princípios a reger o Brasil nas relações internacionais, o princípio da prevalência dos direitos humanos. Trata-se, ademais, da primeira Constituição Brasileira 
a incluir os direitos internacionais no elenco dos direitos constitucionalmente garantidos.

Quanto à indivisibilidade dos direitos humanos, há que se enfatizar que a Carta de 1988 é a primeira Constituição que integra ao elenco dos direitos fundamentais, os direitos sociais, que nas Cartas anteriores restavam pulverizados no capítulo pertinente à ordem econômica e social. Observe-se que, no Direito brasileiro, desde 1934, as Constituições passaram a incorporar os direitos sociais e econômicos. Contudo, a Constituição de 1988 é a primeira a afirmar que os direitos sociais são direitos fundamentais, tendo aplicabilidade imediata. (PIOVESAN, 2014, p. 4I0).

A Constituição, de 1988, buscando proteger em grau máximo os direitos fundamentais, inseriu a cláusula "direitos e garantias individuais" no rol das cláusulas pétreas. Tendo em vista a universalidade e a indivisibilidade dos direitos humanos, o princípio de proibição do retrocesso social e o valor da dignidade humana - somados aos demais princípios constitucionais - conclui-se que esta cláusula contempla, também, os direitos sociais. Estes, portanto, caracterizam-se como direitos intangíveis e irredutíveis, de modo que nem lei ordinária, nem emenda constitucional podem abolir ou suprimir direitos sociais, sob pena de vício de inconstitucionalidade. (PIOVESAN, 2014, p. 4|2).

Assim, a Constituição, de 1988, celebra a reinvenção do marco jurídico normativo brasileiro em matéria de proteção dos direitos humanos, especialmente dos direitos sociais. (PIOVESAN, 20।4, p. 4I3).

Importa destacar que, partindo de uma visão não atomizada dos direitos fundamentais, chega-se à conclusão de que os direitos civis, políticos e sociais encontram-se fortemente entrelaçados. Sob esse prisma, a liberdade passa a ser o fundamento não apenas dos direitos civis e políticos, mas também dos direitos sociais. Nesse sentido, Gerardo Pisarello observa que o fato de o princípio de dignidade estruturar-se enquanto fundamento dos direitos da pessoa implica interdependência e indivisibilidade entre os direitos civis, políticos e sociais. Isso significa que o não atendimento dos direitos sociais básicos pode ter como consequência o esvaziamento dos direitos civis; de modo similar, "poderia afirmar-se que a conquista do direito à alimentação, à habitação ou ao trabalho depende em boa medida da disposição de liberdades civis e políticas que permitam reivindicar tais direitos". (PISARELLO, 2007, p. 40)

Esse entrelaçamento entre direitos sociais e direitos de liberdade parece ser uma das razões pelas quais Pisarello rechaça a percepção histórica dominante relativamente aos direitos sociais. Para o referido autor, "apesar de sua ampla difusão pedagógica, esta representação se assenta em pressupostos que tendem a ser restritivos, excludentes e deterministas e a justificar, ao final, uma proteção desvalorizada dos direitos sociais". (PISARELLO, 2007, p. 19 e 20). 


\section{PATERNALISMOEJUSTIFICAÇÃO}

A ideia de paternalismo decorre do transbordamento do modelo de relação paterno-filial para outros tipos de relações sociais, como, por exemplo, na relação entre Estado e cidadãos, médico e paciente etc. Um tratamento paternalista possui tanto uma dimensão de cuidado como uma dimensão de controle, sendo que o que se questiona é a aplicação do poder paternal a âmbitos sociais que não o das relações entre pais e filhos. (ALEMANY, 2005, p. 266).

Segundo Gerard Dworkin, o paternalismo se constitui na interferência promovida por um Estado ou um indivíduo em outra pessoa, contra a sua vontade, defendida ou motivada sob a alegação de que a pessoa custodiada estará mais bem protegida contra danos. (DWORKIN, 2016).

Stephan Kirste observa que o paternalismo jurídico caracteriza-se como "um tratamento dado a uma pessoa em favor de outra, que interfere em sua autonomia juridicamente protegida". Esta, segundo Kirste, seria uma variante "rígida" do paternalismo, ao lado da qual caminharia uma variante "fraca". Utilizando-se de medidas que visam compensar os déficits de racionalidade, esta última variante objetiva promover a autonomia do indivíduo ao qual se dispensa um tratamento paternalístico. Entretanto, para o autor alemão, identificar o limite entre um paternalismo fraco e um paternalismo relevante juridicamente, não parece ser um problema de simples resolução. (KIRSTE, 2013, p. 73 e 74).

Há de se assinalar que existem distintas concepções de paternalismo. Paulette Dieterlen observa que Dworkin entende que o paternalismo constitui-se de três elementos: i) a interferência na liberdade de ação de determinada pessoa; ii) a coerção; e iii) a presença, ou não, de consentimento. A interferência na liberdade de ação consiste na aplicação de determinadas regulações, leis ou decretos que impõem dificuldades ou mesmo impossibilitam - ao indivíduo para realizar seus planos de vida. A coerção, por seu turno, existe quando uma pessoa não possui liberdade de escolha, atuando de modo a evitar uma ameaça e nos casos em que satisfaçam duas condições: i) que a pena utilizada como ameaça contra o sujeito faça com que determinada ação seja significativamente menos atrativa para ele do que outra; ii) a pessoa entende que se sentiria pior desafiando a ameaça do que se submetendo a ela. (DIETERLEN, I988, p. I8I)

Para Macario Alemany, uma ação paternalista caracteriza-se como o exercício de poder que o sujeito $A$ exerce sobre o sujeito B para obter deste certo comportamento. Entretanto, o que distingue o paternalismo de outras formas de exercício de poder é a finalidade daquele: a ação paternalista visa evitar danos - de tipo físico, psíquico e/ou econômico - ao sujeito tratado paternalisticamente (por exemplo, obrigar um sujeito a parar de fumar para evitar câncer). (ALEMANY, 2005, p. 270).

Também é importante separar o problema que diz respeito à justificação do paternalismo do problema que diz respeito à justificação do chamado "perfeccionismo". (ALEMANY, 2005, p. 270). 
Tanto o termo "beneficiar" como o termo "poder benevolente" são utilizados em sentido amplo, que abarca, por um lado, as ações que têm por objetivo evitar danos, e por outro, têm um sentido que se opõe à ideia de evitar danos. É possível entender essa distinção por meio da delimitação das necessidades básicas dos seres humanos. Isso porque, no caso da haver uma necessidade básica não satisfeita, supõe-se que o indivíduo se encontra abaixo de um limite mínimo de bem-estar de modo que todos seus demais interesses não poderão ser satisfeitos. (ALEMANY, 2005, p. 27I).

Assim, se a finalidade do paternalismo é evitar danos, o termo "beneficiar" é utilizado para aquelas ações que têm por objetivo a promoção dos interesses de bem-estar para além daquele patamar mínimo e, em geral, a promoção de interesses ulteriores que não são reconhecidos pelos indivíduos como tais. Portanto, quando se exerce poder sobre os indivíduos com essa finalidade - promoção de interesses para além do patamar mínimo - estamos diante do que se denomina "perfeccionismo". O perfeccionismo, assim, não se confunde com o paternalismo, tendo em vista que aquele possui dupla dimensão: maximizadora (de benefícios) e moralista, enquanto que o paternalismo possui dimensão minimizadora (de danos) e orientada ao bem-estar. Para aclarar esse ponto, é possível tomar um exemplo de ação paternalista e ação perfeccionista: tornar obrigatória a educação básica, seria uma ação paternalista, enquanto que impor uma educação esmerada em belas artes, por exemplo, seria uma ação perfeccionista. (ALEMANY, 2005, p. 27। e 272).

Sobre esse ponto, Kirste observa que:

A perfectibilidade do ser humano era uma tarefa do Estado paternalista pré-moderno, e não uma preocupação do Estado constitucional liberal. Aperfeiçoar-se é algo que remete somente ao indivíduo em si. A depender do alcance de sua autonomia, deverá o indivíduo justificar-se diante de si próprio e de sua moral ou religião e não diante dos outros. (KIRSTE, 2013, p. 75).

Dieterlen observa que Dworkin define paternalismo também como "a interferência com a liberdade de ação que se justifica por razões concernentes ao bem estar, à felicidade, às necessidades, aos interesses ou valores da pessoa ou pessoas coercionadas". (DIETERLEN, I988, p. I8I).

A partir desse conceito, é possível observar que, se por um lado, i) a ação paternalista interfere na liberdade do indivíduo, por outro, ii) é possível que essa interferência se justifique por razões vinculadas ao bem-estar, necessidade etc.

Entretanto, um dos problemas da noção de paternalismo de Dworkin é que não é claro que toda interferência (paternalista) na liberdade das pessoas seja coercitiva. Nesse sentido, Dieterlen observa que Gert y Culver entendem que há casos de paternalismo em que não há interferência na liberdade de ação nem coerção. (DIETERLEN, 1988, p. 
Como se pode observar, a liberdade é o ponto sensível do paternalismo. Nesse sentido, a crítica de Kirste ao paternalismo - até mesmo ao paternalismo "fraco" - tem como referência a autonomia do indivíduo. Segundo o autor alemão,

paternalismo é a ação em favor de outro contra a sua autonomia. A autonomia legal do outro requer apenas a sua capacidade de autodeterminação, nenhuma completa justificação racional. Quem quer, a nível da razão, o melhor para o outro, pode a ele explicar, convencê-lo ou adverti-lo. Essas não são ações paternalistas, porque observam a autonomia do outro e simplesmente argumentam. A fronteira do paternalismo é ultrapassada, se o conselho, o qual deve advertir o destinatário da autolesão, for obrigatório. Ele só poderia ser justificado se o assessor satisfazer com isso o seu próprio compromisso, que é superior à autodeterminação do beneficiário. $\bigcirc$ paternalismo pode também ser justificado quando a pessoa não está apenas prejudicando a si mesmo, mas ao mesmo tempo, com o dano, violando uma obrigação (fundamental). (KIRSTE, 20।3, p. 85).

Para Kirste, o indivíduo tem o direito de decidir por si só sobre os limites da autodeterminação, sendo que é o próprio sujeito - e não o Estado ou qualquer outro sujeito - que se protege de si mesmo. "Ele se defende também contra o paternalismo 'fraco', porque ele quer decidir autonomamente sobre sua autonomia e não quer depender de critérios que o obriga com padrões de racionalidade". (KIRSTE, 20 I3, p. 86).

Entretanto, tendo em vista a atribuição e os fins do Estado social - uma dimensão do Estado que não está restringida aos valores liberais de liberdade negativa, mas que valoriza a igualdade material por meio de uma justiça distributiva -, é preciso refletir se determinadas ações paternalistas do Estado não estariam justificadas nesse contexto.

A ideologia dominante nos países desenvolvidos é antipaternalista (ALEMANY, 2005, p. 266). Robert Nozick, por exemplo, afirma que "o Estado mínimo é o mais extenso que se pode justificar. Qualquer outro mais amplo viola direitos da pessoa. Ainda assim muitas delas apresentaram razões que alegadamente justificam o Estado mais amplo". (NOZICK, I99I , p. 170)

Contrapondo-se a essa ideologia, Alemany observa que

O valor outorgado à autonomia individual, à democracia e, inclusive, ao sistema de livre mercado parecem descartar a possibilidade de encontrar supostos de paternalismo justificado. Sem embargo, a persistente presença de intervenções que se nos apresentam como plausivelmente justificadas, por um lado, e como paternalistas, por outro, desafiam a esta corrente de pensamento. $\bigcirc$ paternalismo adquire, portanto, uma 
extraordinária relevância teórica. A meu ver, as implicações da justificação do paternalismo constituem junto com uma consideração profunda do alcance do princípio de dano a terceiros, uma poderosa ferramenta contra as diferentes teorias do Estado mínimo que emanam dessa fonte de muitos canos em que se converteu o liberalismo político. (ALEMANY, 2005, p. 266).

A relevância teórica do paternalismo, assim, decorre do fato de que as implicações da justificação de determinadas ações paternalistas constituem - somadas a uma consideração aguda do alcance do princípio do dano a terceiros - importante instrumento contra as variadas teorias do Estado mínimo derivadas do liberalismo político. (ALEMANY, 2005, p. 266).

$\bigcirc$ neoconservadorismo e sua luta para desmontar o Estado Social - pois considerado como uma forma moralmente injustificável de agressão paternalista -, e a existência no interior das sociedades de ações claramente paternalistas (por exemplo, proibição de vendas de drogas e obrigatoriedade do uso do cinto de segurança) promoveram uma atualização da leitura da obra de John Stuart Mill, reacendendo a polêmica sobre "se se deve ou não admitir como único princípio de justificação ética da coação estatal a prevenção e o castigo de danos infligidos a terceiros ou se também existem tipos de paternalismos que são justificáveis eticamente". (VALDÉS, I988, p. 156).

Como já apontado, uma das críticas ao paternalismo diz respeito à autonomia da pessoa - autonomia como capacidade de escolha. Entretanto, parece difícil sustentar que intervenções paternalistas, necessariamente, ferem a autonomia das pessoas.

Douglas Husak oferece como exemplo a seguinte suposição: suponha-se que o uso de determinadas drogas diminua a capacidade de escolha. Nesse caso, aqueles que defendem o valor da autonomia como capacidade de escolha teriam de se posicionar a favor de medidas racionais que induzam coativamente as pessoas a não consumir tais drogas, ainda que tais medidas sejam chamadas de paternalistas. (VALDÉS, I988, p. |61).

Outro ponto importante, destacado por Dieterlen, é que se faz necessário distinguir paternalismo de políticas de justiça distributiva. Referindo-se ao México, a autora destaca que a história deste país está repleta de exemplos de políticas paternalistas, mas, de outra forma, é preciso reconhecer que em um país com desigualdades sociais profundas como o México - há muitas políticas que são o resultado de uma mínima justiça distributiva. (DIETERLEN, 1988, p. 190)

Nesse ponto, ganha relevância o aspecto histórico que se refere ao modo como se obteve determinada legislação. "Em muitos casos algumas proteções e garantias que se encontram em uma Constituição não são concessões que realiza o Estado para o bem próprio dos cidadãos, mas são ganhos obtidos por certos setores da sociedade. Um sem-número de leis que protegem os campesinos e os trabalhadores foram obtidas 
desta forma" (DIETERLEN, I988, p. 190).

A discussão sobre paternalismo deve considerar, ainda, a presença - ou ausência do consentimento do destinatário da ação paternalista.

Se se põe o acento na necessidade/importância do respeito à autonomia da pessoa, a argumentação que visa justificar determinadas ações paternalistas deve centrar-se no consentimento - expresso ou hipotético - da pessoa à qual se dispensa um tratamento paternalista. Este é o caminho percorrido por Dworkin ao afirmar que "a noção básica de consentimento é importante e me parece ser a única via aceitável para tratar de delimitar a área do paternalismo justificado". (VALDÉS, 1988, p. I62 e I63).

Por sua vez, Valdés afirma que a condição necessária - ainda que não suficiente -, para a justificação de medidas paternalistas, é a falta de competência básica. Segundo o mesmo autor, pode-se dizer que uma pessoa carece de competência básica nos seguintes casos:

\begin{abstract}
a) quando ignora elementos relevantes da situação em que tem de atuar (tal é o caso de quem desconhece os efeitos de certos medicamentos ou drogas ou de quem se dispõe a cruzar uma ponte e não sabe que está quebrada, para usar o exemplo de Mill; b) quando sua força de vontade é tão reduzida ou está tão afetada que não pode levar a cabo suas próprias decisões (é o caso de Ulisses, o dos alcoolistas e dependentes químicos); c) quando suas faculdade mentais estão temporária ou permanentemente reduzidas (a estes casos se referem as disposições jurídicas que proíbem os duelos, ou as relacionadas com a curatela dos débeis mentais); d) quando atua sob compulsão (por exemplo, sob hipnose ou sob ameaça). (VALDÉS, 1988, p. 166)
\end{abstract}

Entretanto, a mera verificação de que alguém é incompetente básico não é condição suficiente para justificar uma intervenção paternalista. Isso porque a intervenção paternalista requer, ainda, um interesse benevolente no incompetente básico, que tenha por objetivo superar as desvantagens ligadas à incompetência básica para o próprio incompetente, ou seja, evitar que não cause dano a si mesmo. (VALDÉS, 1988 , p. 166).

A partir dessa afirmação, é possível observar que a intervenção paternalista supõe uma relação de desigualdade em muitos casos. Isso deriva da própria noção de incompetência básica. Mas é preciso frisar que o objetivo da intervenção paternalista justificável é precisamente a superação da desigualdade. (VALDÉS, 1988, p. 167).

Portanto, a aceitação dessas condições para justificação do paternalismo jurídico "permitem interpretá-lo não só como moralmente permitido, mas também é possível afirmar que está moralmente ordenado como um meio eficaz para a redução das desigualdades. É nesse sentido um complemento necessário do princípio do dano a terceiros suscetível de ser interpretado como uma obrigação moral positiva". (VALDÉS, 
1988, p. 170).

Ainda, ao analisar a crítica ao paternalismo, é preciso frisar que um mínimo de bemestar social e educação - além de uma cultura democrática amadurecida - são condições da democracia. Nesse sentido, uma pessoa não pode exercer seus direitos de liberdade negativa se não tiver acesso aos bens - saúde, educação, alimentação etc. necessários para sua liberdade (KIRSTE, 20 I6, p. I4).

\section{CONCLUSÃO}

Se, por um lado, a crítica antipaternalista apresenta-se como importante ferramenta para a garantia da autonomia do indivíduo, por outro, sua utilização parece exigir certa cautela. A crítica do paternalismo tem sua origem no liberalismo sendo, portanto, construída no contexto de países do norte. Esses países desenvolveram fortemente o Estado Social, sobretudo após a segunda grande guerra, na modalidade conhecida como Estado de Bem-Estar Social (Welfare State). Assim, parece não ser adequado importar uma crítica desenvolvida dentro de Estados nos quais os níveis de satisfação dos direitos sociais são significativos, aplicando-a sem ressalvas aos países em desenvolvimento, nos quais, ainda nos dias atuais, significativas parcelas das populações encontram-se à margem da garantia de direitos fundamentais das mais variadas espécies.

Como se procurou demonstrar, a crítica antipaternalista se dirige àquelas intervenções que afetam a liberdade da pessoa tratada paternalisticamente. Dessa forma, ela visa proteger o direito fundamental à liberdade, e mais especificamente a autonomia do indivíduo.

Todavia, é preciso considerar que os direitos fundamentais mantêm entre si uma relação de complementaridade. Isso significa que, por exemplo, o não atendimento de um direito social - como o direito à alimentação ou à saúde - implica violação do direito de liberdade, por razões óbvias.

A crítica do paternalismo, portanto, precisa ser construída sem que se desconsidere a indivisibilidade dos direitos fundamentais e suas relações de interdependências sobretudo dos direitos civis, políticos e sociais. Isso porque os direitos de liberdade ficam severamente prejudicados quando direitos sociais básicos, como saúde, educação e alimentação, não são satisfatoriamente atendidos.

Por essa razão, entende-se que a concretização das tarefas do Estado Social é fundamental para autonomia dos indivíduos, haja vista a apontada relação de interdependência entre os direitos fundamentais de defesa e prestacionais.

Reconhecendo a complexidade que caracteriza as sociedades nos dias atuais, observa-se, ainda, que os direitos fundamentais mantêm estreitas relações também com a democracia, de modo que ambos conformam-se reciprocamente. É certo que os direitos fundamentais não podem ser garantidos num regime não democrático, assim como é certo que não se pode alcançar uma democracia substancial em que a proteção e a realização dos direitos fundamentais sejam deficientes. 
De outro modo, o Estado Social e Democrático de Direito, enquanto garantidor dos direitos fundamentais, não pode atuar de qualquer modo, a pretexto de realizar o melhor para os seus cidadãos, interferindo indevidamente na autonomia dos indivíduos. Como o direito de liberdade é, também ele, um direito fundamental, toda intervenção estatal na autonomia do sujeito precisa estar justificada, seja pelo consentimento expresso ou hipotético - do indivíduo tratado paternalisticamente, seja pela necessidade de se evitarem danos a terceiros.

Estado Social, portanto, tem a tarefa de realizar de modo satisfatório os direitos fundamentais sociais, ao mesmo tempo em que deve respeitar o direito à liberdade dos indivíduos, garantindo o quanto possível o direito que cada pessoa tem de definir autonomamente seus próprios planos de vida.

\section{REFERÊNCIAS}

ALEMANY, Macario. El Concepto y la Justificación del Paternalismo. Doxa, Cuadernos de Filosofía del Derecho, 28. 2005.

BONAVIDES, Paulo. Curso de Direito Constitucional. 22. ed. São Paulo: Malheiros. 2008.

CALLEJÓN, Francisco Ballaguer. A Interação entre Democracia e Direitos no Constitucionalismo e sua Projeção Supranacional e Global. Revista Direito Público, n. 49. Jan.-fev/20।3.p. 2/2. Disponível e m $<$ http://www.direitopublico.idp.edu.br/index.php/direitopublico/article/view/I390/I I $98>$. Acesso em 21// I// 5 .

CANOTILHO, José Joaquim Gomes. Direito Constitucional e Teoria da Constituição. 4. ed. Coimbra: Almedina, 2000.

CORTINA, Adela. Cidadãos do Mundo. Para uma teoria da cidadania. São Paulo: Loyola, 2005.

DALLARI, Dalmo de Abreu. Elementos de Teoria Geral do Estado. 20. ed. São Paulo: Saraiva, 1998.

DIETERLEN, Paulette. Paternalismo y Estado de Bienestar. Doxa, Cuadernos de Filosofía del Derecho, 5. 1988.

DWORKIN, Gerard. "Paternalism". The Stanford Encyclopedia of Philosophy. Edição de inverno de 2016 promovida por Edward N. Zalta. $<$ https://plato.stanford.edu/archives/win20 16/entries/paternalism> Acesso em: 8 de fevereiro de 2017. 
KIRSTE, Stephan. Autonomia e direito à autolesão. Para uma crítica do paternalismo. Revista de Direitos Fundamentais e Democracia, Curitiba, v. I4, n. I4, julho/dezembro de 2013.

KIRSTE, Stephan. O Direito Humano Fundamental à Democracia. Revista de Direitos Fundamentais e Democracia, Curitiba, v. 20, n. 20, julho/dezembro de 2016.

MENDES, Gilmar Ferreira; BRANCO, Paulo Gustavo Gonet. Curso de Direito Constitucional. 6. ed. São Paulo: Saraiva, 201 I , p.710.

NOZICK, Robert. Anarquia, Estado e Utopia. Trad. Ruy Jungmann. Rio de Janeiro: Jorge Zahar, 1991.

PIOVESAN, Flávia. Proteção dos Direitos Sociais no Brasil: desafios e perspectivas. In: CLÈVE, Clèmerson Merlin; FREIRE; Alexandre (coords.). Direitos Fundamentais e Jurisdição Constitucional. São Paulo: Revista dos Tribunais, 2014.

PIRES, Luis Manuel Fonseca. O Estado Social e Democrático e o Serviço Público. Um breve ensaio sobre liberdade, igualdade e fraternidade. Belo Horizonte: Fórum, 2012. p. 96.

PISARELLO, Gerardo. Los Derechos Sociales y sus Garantías. Elementos para una reconstrucción. Madrid: Trotta, 2007

SARLET, Ingo Wolfgang, A Eficácia dos Direitos Fundamentais. Uma Teoria Geral dos Direitos Fundamentais na Perspectiva Constitucional. 10. ed. Porto Alegre: livraria do Advogado, 2009.

Os Direitos Fundamentais Sociais na Constituição de 1988. Revista Diálogo Jurídico. Ano I, v. I, n. ${ }^{\circ}$ I. Abril/200I. p. 3 e 4. Disponível em http://www.direitopublico.com.br/pdf_seguro/revista-dialogo -juridico-0 I-200 I-ingosarlet.pdf. Acesso em | 4// I//4.

SILVA, José Afonso da. Curso de Direito Constitucional Positivo. 24. ed. São Paulo: Malheiros, 2005.

STRECK, Lenio Luiz; MORAIS, José Luís Bolzan. Ciência Política e Teoria Geral do Estado. 3. ed. Porto Alegre: Livraria do Advogado, 2003.

VALDÉS, Ernesto Garzón. És Eticamente Justificable el Paternalismo? Doxa, Cuadernos de Filosofía del Derecho, 5, 1988. 
ZOLO, Danilo. Teoria e Crítica do Estado de Direito. In: COSTA, Pietro; ZOLO, Danilo (Orgs). O Estado de Direito. História, teoria, crítica. São Paulo: Martins Fontes, 2006. 